\title{
Comparison of the intraocular pressure lowering effect of latanoprost and a fixed combination of timolol-pilocarpine eye drops in patients insufficiently controlled with $\beta$ adrenergic antagonists
}

Jean-Philippe Nordmann, Mats Söderström, Jean-François Rouland, François Malecaze, the French Latanoprost Study Group, and the Swedish Latanoprost Study Group

\begin{abstract}
Aims-To compare the effect on intraocular pressure (IOP) of latanoprost monotherapy and timolol-pilocarpine in patients with glaucoma or ocular hypertension with inadequately controlled IOP on topical $\beta$ adrenergic antagonists.

Methods-This was a multicentre, randomised, observer masked, 6 week study performed in France and Sweden. 23 centres enrolled 237 patients with glaucoma or ocular hypertension and an IOP of at least $22 \mathrm{~mm} \mathrm{Hg}$ on treatment with topical $\beta$ adrenergic antagonists, alone or in combination. After a 21 day run in period on timolol $0.5 \%$ twice daily, patients were randomised either to latanoprost $0.005 \%$ once daily or to a fixed combination of timolol-pilocarpine twice daily. Changes in mean diurnal IOP from the baseline to the 6 week visit were determined with an analysis of covariance.

Results-Mean diurnal IOP was statistically significantly decreased from baseline in both groups $(p<0.001)$. Switching to latanoprost treatment reduced mean diurnal IOP by 5.4 (SEM 0.3) $\mathrm{mm} \mathrm{Hg}$ (ANCOVA -22\%) and switching to timolol-pilocarpine treatment reduced mean diurnal IOP by $4.9(0.4) \mathrm{mm} \mathrm{Hg}$ $(-20 \%)$. Blurred vision, decreased visual acuity, decreased twilight vision, and headache were statistically significantly more frequent in the timolol-pilocarpine group.

Conclusions-Latanoprost monotherapy was at least as effective as fixed combination timolol-pilocarpine twice daily treatment in reducing mean diurnal IOP in patients not adequately controlled on topical $\beta$ adrenergic antagonists. Latanoprost was better tolerated than timololpilocarpine regarding side effects. These results indicate that a switch to latanoprost monotherapy can be attempted before combination therapy is initiated. (Br F Ophthalmol 2000;84:181-185)
\end{abstract}

Latanoprost, a prostaglandin $\mathrm{F}_{2 \alpha}$ analogue, has proved to be an effective ocular hypotensive drug. ${ }^{1-7}$ Its main mechanism for reducing intraocular pressure (IOP) is an increase in the uveoscleral outflow. When administered to monkey eyes latanoprost markedly increased uveoscleral outflow, ${ }^{8}$ and a corresponding effect has indirectly been demonstrated in humans. ${ }^{9}$ Latanoprost has not been found to alter the aqueous humour production to a clinically significant extent. ${ }^{910}$ In long term studies latanoprost, when applied as a once daily dose of a $0.005 \%$ concentration, reduced IOP at least as effectively as $\beta$ adrenergic antagonists. ${ }^{1-3}$ Previous studies have shown that adding $\mathrm{PGF}_{2 \alpha}$ isopropyl ester to timolol caused a further reduction of the IOP..$^{11}{ }^{12} \mathrm{~A}$ marked additional IOP reducing effect of latanoprost added to timolol was also seen in a 3 month study by Alm et $a l,{ }^{1}$ in which once daily was found to be the optimal dosage regimen for latanoprost.

In many patients topical $\beta$ adrenergic antagonists alone do not sufficiently lower IOP, and additional medications have to be prescribed. ${ }^{13}$ In current practice, pilocarpine is frequently used as "add on" therapy and it may be of interest to know whether a simple switch from $\beta$ adrenergic antagonist to latanoprost is as effective. Administration of several medications may be inconvenient for the patient, ${ }^{14}$ and long term maintenance with monotherapy in the management of glaucoma would, therefore, be advantageous for the patient.

The purpose of the present study was to compare the effect on IOP of treatment with latanoprost or timolol-pilocarpine in glaucoma patients or patients with ocular hypertension inadequately controlled on topical $\beta$ adrenergic antagonists. In addition, ocular and systemic safety variables were monitored and reported throughout the 6 week study period.

\section{Patients and methods}

This multicentre study was designed as a 6 week randomised, observer masked comparison of latanoprost with timolol-pilocarpine treatment. A total of 23 centres were involved in the study; 17 centres in France and six centres in Sweden. After obtaining approval from the appropriate regulatory authorities and ethics committees for each centre, signed informed consent was obtained from all patients before entering the study. The study protocol followed the guidelines of the Declaration of Helsinki. After a run in period of at least 21 days on timolol $0.5 \%$ (Blocadren, Merck) 
Table 1 Schedule of examinations and procedures

\begin{tabular}{|c|c|c|c|c|c|c|c|c|}
\hline \multirow[b]{2}{*}{ Examination * } & \multirow{2}{*}{$\begin{array}{l}\text { Within } 4 \\
\text { weeks of } \\
\text { baseline }\end{array}$} & \multicolumn{3}{|l|}{ Baseline } & \multirow{2}{*}{$\begin{array}{l}2 \text { weeks } \\
8 / 9 \text { am }\end{array}$} & \multicolumn{3}{|l|}{6 weeks } \\
\hline & & $8 / 9 \mathrm{am}$ & 12 nоon & $4 p m$ & & $8 / 9 \mathrm{am}$ & 12 noon & $4 p m$ \\
\hline $\begin{array}{l}\text { Medical and ocular } \\
\text { history }\end{array}$ & $\mathrm{X}$ & & & & & & & \\
\hline $\begin{array}{l}\text { Visual acuity and } \\
\text { refraction }\end{array}$ & $\mathrm{X}$ & & $\mathrm{X}$ & & $\mathrm{X}$ & & $\mathrm{X}$ & \\
\hline Slit lamp examination & $\mathrm{X}$ & & $\mathrm{x}$ & & $\mathrm{x}$ & & $\mathrm{X}$ & \\
\hline Intraocular pressure & $\mathrm{X}$ & $\mathrm{X}$ & $\mathrm{X}$ & $\mathrm{X}$ & $\mathrm{X}$ & $\mathrm{X}$ & $\mathrm{X}$ & $\mathrm{X}$ \\
\hline Ophthalmoscopy & $\mathrm{X}$ & & & & & & $\mathrm{X}$ & \\
\hline Visual field & $\mathrm{X}$ & & & & & & $\mathrm{X}$ & \\
\hline Symptomatology & $\mathrm{X}$ & & $\mathrm{X}$ & & $\mathrm{X}$ & & $\mathrm{X}$ & \\
\hline
\end{tabular}

^8 am measurement (Sweden), 9 am measurement (France).

twice daily, the patients were randomised to two parallel study groups; one group switched from timolol to latanoprost $0.005 \%$ (Xalatan, Pharmacia and Upjohn $\mathrm{AB}$ ) once daily (evening), and the other group switched from timolol to a fixed combination of timolol $0.5 \%$-pilocarpine $2 \%$ (Timpilo, Merck) twice daily.

Patients with a minimum age of 18 years and diagnosed with unilateral or bilateral primary open angle glaucoma, capsular glaucoma, pigmentary glaucoma, or ocular hypertension were eligible for the study. In addition, the patients should be on therapy with topical $\beta$ adrenergic antagonists, alone or in combination, and the IOP inadequately controlled on current therapy at the time for enrolment. An IOP of at least $22 \mathrm{~mm} \mathrm{Hg}$ at the prestudy visit was set as an inclusion criterion. The patients requiring bilateral treatment had to fulfil all eligibility criteria for both eyes to be included. However, if only one eye fulfilled the inclusion criteria that eye was included as the study eye but the fellow eye could be treated with allocated study therapy provided that no exclusion criteria were met.

Exclusion criteria were use of pilocarpine or latanoprost within the past 2 years or at present time in the study eye, any ocular medications other than for glaucoma, closed or barely open anterior chamber angle, severe trauma at any time, current use of contact lenses, ocular inflammation within the past 3 months, ocular surgery, or argon laser trabeculoplasty within the past 3 months, any condition preventing reliable applanation tonometry, currently pregnant or nursing, considering pregnancy, or inability to adhere to the protocol design. The patients were allowed to be on systemic $\beta$ adrenergic antagonists at the inclusion into the study. However, no such medication could be initiated or altered during the study.

The schedule of examinations and procedures is presented in Table 1 . At the prestudy visit medical and ocular history were taken. Perimetry was carried out unless recently performed. Visual acuity and refraction, slit lamp examination, evaluation of conjunctival hyperaemia, ophthalmoscopy, and measurement of the IOP were performed. This visit took place within 4 weeks before the study start, and the patients were included after this assessment for eligibility. In order to establish a reliable baseline, the patients were switched from their prescribed therapy of $\beta$ adrenergic antagonists to timolol $0.5 \%$ eye drops twice daily at least 21 days before study start. If they were on combination therapy they switched to timolol eye drops and continued using the additional medication, but the latter one was later discontinued to allow for washout of this drug. The washout period was 7 days for carbonic anhydrase inhibitors and 14 days for adrenergic agents. During the study period of 6 weeks, there were three scheduled visits; at baseline, after 2 weeks, and after 6 weeks. On the baseline day the patients were assigned to treatment by computer generated randomisation, stratified for each centre and performed in blocks of consecutive patients within each centre. The dosing schedule for the latanoprost group was one drop in the evening at approximately $7 \mathrm{pm}$, while the dosing for the fixed combination of timolol-pilocarpine was one drop in the morning at approximately 7 am and one drop in the evening at approximately $7 \mathrm{pm}$.

A Goldmann applanation tonometer was used for the IOP measurements. In each eye three measurements were performed, starting with the right eye and alternating between the eyes. The mean of the three measurements was used in the statistical analyses. Best corrected Snellen visual acuity and refractive error were determined at each visit, and a slit lamp examination was performed. During the slit lamp examination, the presence of flare in the anterior chamber was graded as none, mild, moderate, or severe, while the presence of cells in a slit of $2 \mathrm{~mm}$ width was graded as none (1-2 cells), mild ( $3-5$ cells), moderate (6-20 cells), or severe ( $>20$ cells). At the prestudy visit and at the 6 week visit ophthalmoscopy was performed through dilated pupils.

Throughout the study adverse events were carefully monitored. An adverse event was defined as any undesirable event occurring in a subject regardless if it was considered related to the investigational drugs. A serious adverse event was defined as potentially fatal, life threatening, sight threatening, permanently disabling, requiring hospitalisation, or requiring intervention to prevent permanent impairment or damage.

An analysis of covariance (ANCOVA) was performed with diurnal IOP change at week 6 from baseline as response variable, baseline diurnal IOP as covariate and group and centre as factors. The diurnal IOP was defined as the mean value of measurements at $8 \mathrm{am}, 12$ noon,

Table 2 Demographic characteristics of the patients

\begin{tabular}{lll}
\hline Characteristics & $\begin{array}{l}\text { Latanoprost } \\
(n=118)\end{array}$ & $\begin{array}{l}\text { Timolol-pilocarpine } \\
(n=119)\end{array}$ \\
\hline Age (years) & $63(11.9)$ & $64(13.2)$ \\
$\quad$ Mean (SD) & $28-89$ & $25-94$ \\
$\quad$ Range & & \\
Sex & 62 & 64 \\
$\quad$ Female & 56 & 55 \\
$\quad$ Male & & \\
Glaucoma diagnosis & & \\
$\quad$ Primary open angle & 62 & 78 \\
$\quad$ glaucoma & 16 \\
$\quad$ Exfoliation glaucoma & 21 & 1 \\
$\quad$ Pigmentary glaucoma & 6 & 23 \\
Ocular hypertension & 26 & 1 \\
$\quad$ Mixed glaucoma & 3 & \\
\hline
\end{tabular}


Table 3 Reasons for patient withdrawal from the study

\begin{tabular}{lll}
\hline Reasons & $\begin{array}{l}\text { Latanoprost } \\
(n=5)\end{array}$ & $\begin{array}{l}\text { Timolol-pilocarpine } \\
(n=13)\end{array}$ \\
\hline Blurred vision and/or decreased visual acuity & 0 & 6 \\
Headache & 0 & 2 \\
Allergic conjunctivitis & 1 & 2 \\
Treatment mistake, surgery required & 1 & 0 \\
Vertigo & $1^{\star}$ & 0 \\
Poor patient compliance & 0 & 1 \\
Patient lost to follow up & 1 & 2 \\
Patient decided to withdraw without specifying reason & 1 & 0 \\
\hline
\end{tabular}

$\star$ Reported as serious adverse event.

Table 4 IOP (mm Hg), mean (SD) in each group at each measurement

\begin{tabular}{lll}
\hline Time & $\begin{array}{l}\text { Latanoprost } \\
(n=102)\end{array}$ & $\begin{array}{l}\text { Timolol-pilocarpine } \\
(n=95)\end{array}$ \\
\hline Baseline & & \\
$8 / 9$ am & & \\
12 noon & $24.7(4.5)$ & $24.8(3.8)$ \\
$4 \mathrm{pm}$ & $24.6(3.9)$ & $24.3(4.1)$ \\
Week 2 & $23.7(3.7)$ & $23.4(3.8)$ \\
$\quad 8 / 9 \mathrm{am}^{\star}$ & $18.9(3.4)$ & $19.4(4.0)$ \\
Week 6 & & \\
$8 / 9 \mathrm{am}^{\star}$ & $19.4(3.7)$ & $19.2(4.8)$ \\
$12 \mathrm{noon}$ & $19.3(3.6)$ & $19.7(4.2)$ \\
$4 \mathrm{pm}$ & $18.5(3.1)$ & $19.4(3.5)$ \\
\hline 8 am measurement (Sweden), 9 am measurement (France).
\end{tabular}

and $4 \mathrm{pm}$ (Sweden) or 9 am, 12 noon, and $4 \mathrm{pm}$ (France). If both eyes of a patient were studied, the mean IOP of both eyes was used in the analysis.

\section{Results}

Of the 237 patients included in the study, 118 patients were randomised to the latanoprost treatment group and 119 patients to the timolol-pilocarpine treatment group. The demographic characteristics of the two treatment groups are presented in Table 2 . There was no major difference between the two treatment groups with respect to age, sex, or diagnosis with the exception that there were six patients with pigmentary glaucoma in the latanoprost group and only one patient with this type of glaucoma in the timolol-pilocarpine group.

A comparison of the mean diurnal IOP after 6 weeks of treatment to the mean diurnal IOP at baseline was performed for 197 patients; 102 patients in the latanoprost group and 95 patients in the timolol-pilocarpine group. Five patients in the latanoprost group and 13 patients in the timolol-pilocarpine group were withdrawn before the study termination. The reasons for withdrawal are listed in Table 3. Thirteen patients in the latanoprost group and nine patients from the timolol-pilocarpine group were excluded from the analysis of efficacy owing to protocol violations; for example, if the eye drops were not taken as stated in the protocol or if there were unacceptable deviations in tonometry times.

The mean IOP at each measurement for the two treatment groups is presented in Table 4 . In Table 5 the percentage reductions of baseline IOP at 6 weeks are presented. The changes in mean diurnal IOP from the baseline to the 6 week visit, determined with ANCOVA, are presented in Figure 1. Switching from timolol $0.5 \%$ twice daily to latanoprost $0.005 \%$ once daily caused a statistically significant reduction in mean diurnal IOP of 5.4 (SEM
$0.3) \mathrm{mm} \mathrm{Hg}(\mathrm{p}<0.001)$, and switching from timolol $0.5 \%$ twice daily to timolol-pilocarpine twice daily caused a statistically significant reduction in mean diurnal IOP of 4.9 (0.4) $\mathrm{mm} \mathrm{Hg}(\mathrm{p}<0.001)$. The change in treatment in these groups thus caused a reduction corresponding to $22 \%$ and $20 \%$, respectively, of the mean diurnal baseline IOP while on timolol. No statistically significant difference in mean diurnal IOP was found between the two groups at the 6 week visit ( $p=0.24$; ANCOVA).

Ocular and systemic adverse events are presented in Table 6. Withdrawn patients were included until their last visit. Most of the events were reported as mild. The occurrence of the side effects-blurred vision, decreased visual acuity, decreased twilight vision, and headache-was statistically significantly $(\mathrm{p}<0.001)$ more frequent in the timololpilocarpine group than the latanoprost group. There was no statistically significant difference in the occurrence of conjunctival hyperaemia, corneal punctate erosions, or dizziness between the two treatment groups. Serious adverse events were reported in six patients, but a change of the study medication was not required in any of these patients. In the latanoprost group one patient developed vertigo, one patient was diagnosed with a breast tumour, and a third patient was found to have an area of retinal pigmentation. The pigmentation was found in the periphery of the study eye and was first noted at the 6 week visit when the last dose of the study medication had already been taken. The patient was extensively examined and followed for 12 months, and since no change in the retinal pigmentation could be found during this time period, the suspicion of a newly developed retinal change was dismissed. In the timolol-pilocarpine group one patient was hospitalised for thyroidectomy and in two patients the visual fields at the 6 week visit were decreased.

No cells or flare in the anterior chamber was reported for any patient during the study. Slit lamp examinations did not reveal any changes in the iris pigmentation.

Table 5 Percentage reductions of baseline IOP at 6 weeks

\begin{tabular}{lll}
\hline Time & $\begin{array}{l}\text { Latanoprost } \\
(n=102)\end{array}$ & $\begin{array}{l}\text { Timolol-pilocarpine } \\
(n=95)\end{array}$ \\
\hline $8 / 9 \mathrm{am}^{\star}$ & $21 \%$ & $23 \%$ \\
$12 \mathrm{noon}$ & $22 \%$ & $19 \%$ \\
$4 \mathrm{pm}$ & $22 \%$ & $17 \%$ \\
\hline
\end{tabular}

^8 am measurement (Sweden), 9 am measurement (France).

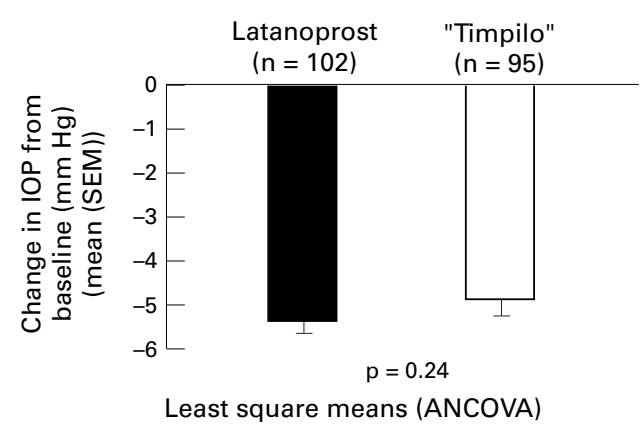

Figure 1 Diurnal IOP reduction at 6 weeks (mean (SEM)) compared with baseline. 
Table 6 Number of ocular and systemic adverse events reported during the study (withdrawn patients included)

\begin{tabular}{lll}
\hline Adverse event & Latanoprost & Timolol-pilocarpine \\
\hline Ocular & $(\mathrm{n}=39)$ & $(\mathrm{n}=94)$ \\
Ocular discomfort* & 33 & 70 \\
Blurred vision & 2 & 54 \\
Decreased visual acuity & 4 & 18 \\
Decreased twilight vision & 1 & 14 \\
Visual field & & \\
$\quad$ changes/scotoma & 4 & $11 \dagger$ \\
Photophobia & 0 & 9 \\
Eyelid pain and discomfort & 2 & 9 \\
Conjunctival hyperaemia & 7 & 5 \\
Increased IOP & 1 & 3 \\
Punctate corneal erosions & 2 & 0 \\
Conjunctivitis & 1 & 2 \\
Other & 13 & 12 \\
Systemic & $(\mathrm{n}=11)$ & $(\mathrm{n}=36)$ \\
Headache & 4 & 25 \\
Dizziness & 1 & 4 \\
Influenza & 4 & 1 \\
Vertigo/imbalance & $1 \dagger$ & 4 \\
Nausea & 0 & 1 \\
Other & $3 \dagger$ & $9 \dagger$ \\
\hline
\end{tabular}

In parenthesis, $\mathrm{n}=$ number of patients reporting adverse events. * Ocular discomfort includes burning, itching, tearing, dry eye, stinging, foreign body eye sensation, and eye pain. †Some events reported as serious adverse event, a total of six patients for both treatments groups. Please see text for explanation.

\section{Discussion}

Combination of two drugs or more is common in the treatment of glaucoma. As a rule a drug that increases outflow, such as latanoprost or pilocarpine, preferably is combined with a drug that reduces inflow, such as $\beta$ adrenergic antagonists or carbonic anhydrase inhibitors. However, multipharmacy may be inconvenient for the patient. ${ }^{14}$ and can result in poor compliance. Therefore, it is of great importance to consider the option of switching a patient from one monotherapy to another monotherapy when the IOP is inadequately controlled instead of just adding another drug to the first treatment. In clinical practice the administration of eye drops from only one dropper bottle is convenient for the patient, and latanoprost as well as timolol-pilocarpine represent this treatment regimen.

In the present study patients with glaucoma or ocular hypertension with IOP inadequately controlled on current therapy with topical $\beta$ adrenergic antagonists, alone or in combination, were switched to treatment with latanoprost once daily or timolol-pilocarpine twice daily. To reduce the risk that a change in treatment compliance was interpreted as a drug effect, a run in period of a minimum of 21 days on timolol twice daily before the baseline visit was incorporated into the study design.

Mean diurnal IOP was considered a relevant measure of clinical efficacy for comparing the two different treatment groups after 6 weeks of therapy. The rationale for choosing this variable was that the study would then include IOP measurements at 13,17, 21 (Sweden) hours and at 14, 17, 21 (France) hours after the last dose of latanoprost, and at 1, 5, 9 (Sweden) hours and 2, 5, 9 (France) hours after the last dose of the fixed combination timololpilocarpine. There is no noticeable peak or trough effect after each dose of latanoprost or timolol since they have a long duration of action, but pilocarpine has a shorter duration of action. However, at each time point in the study comparable or more efficient IOP reduction was achieved with latanoprost than with timolol-pilocarpine.

The results of the study show that latanoprost $0.005 \%$ applied topically once daily is at least as effective in reducing the IOP as timolol-pilocarpine applied twice daily. Switching from timolol to latanoprost reduced mean diurnal IOP by $22 \%$, and switching from timolol to timolol-pilocarpine reduced mean diurnal IOP by $20 \%$. This pressure reduction is nearly of the same magnitude as that seen when latanoprost was given to previously untreated patients with a similar IOP at baseline. ${ }^{2-4}{ }^{6}$ The lack of adequate IOP control according to the inclusion criteria might indicate selection of non-responders to timolol, but most of the patients had responded well to timolol previously and the lack of IOP control was assumed to be due to progression of the disease. Some of the patients had been on timolol for several years and as timolol is known to lose some of its initial effect, ${ }^{15}$ it might be possible that the effect of timolol in these patients was less pronounced than it had been initially. An effect on IOP of systemic treatment with $\beta$ adrenergic antagonists could explain the marked effect of switching from timolol to latanoprost since part of the effect on aqueous flow could then be retained by the oral dose. However, this was not the case, only two patients treated with latanoprost were on systemic $\beta$ adrenergic antagonists.

Aqueous humour flow and IOP have been found to increase slowly after discontinuing timolol in chronic users since the effect of timolol is gradually lost during the first 4 weeks after cessation of therapy ${ }^{16}$ It might be possible that some of the timolol effect was retained throughout the study in the group switching from timolol to latanoprost treatment. There was however, no difference between the effect on the morning IOP at 2 and 6 weeks after the switch from timolol to latanoprost and therefore no obvious indication of a slow loss of effect of timolol in these patients.

The fixed combination of timololpilocarpine twice daily has previously been compared with timolol twice daily plus pilocarpine three times daily in patients with open angle glaucoma. ${ }^{17}$ The fixed combination drug reduced IOP as effectively as the two drugs given separately. This would indicate that switching from timolol to latanoprost monotherapy, which in the present study was at least as effective as switching from timolol to fixed combination timolol-pilocarpine, should be at least as effective as treatment with timolol plus pilocarpine taken separately.

The number of patients withdrawn from the study in the timolol-pilocarpine treatment group was almost three times higher than in the latanoprost treatment group (13 and five patients, respectively). The most common reasons for withdrawal were blurred vision and/or decreased visual acuity in the timololpilocarpine group. Overall, the occurrence of blurred vision, decreased visual acuity, decreased twilight vision, and headache was statistically significantly lower in the latano- 
prost group compared with the timololpilocarpine group. The total number of adverse events was three times higher with timololpilocarpine treatment compared with latanoprost treatment.

In conclusion, we found that switching to latanoprost monotherapy in patients not adequately controlled on timolol treatment was at least as effective in reducing the diurnal IOP as substituting timolol with the fixed combination timolol-pilocarpine. Latanoprost was better tolerated than timolol-pilocarpine regarding the frequency of side effects. The result of this study indicates that a switch to latanoprost monotherapy may be attempted before combination therapy is initiated.

\section{Appendix}

MEMBERS OF THE FRENCH LATANOPROST STUDY GROUP Coordinating investigator: Jean-François Rouland, Hôpital Huriez, Lille.

Principal investigators: Michel Arnoux, Fondation Hôpital Saint Joseph, Marseille; Christophe Baudoin, Hôpital A Paré, Boulogne; Alain Bron, Hôpital Général, Dijon; Jacques Flament, Hôpital Civil, Strasbourg; Denis Gruber, 34 Place de 1'Hotel de Ville, Le Havre; Pascale Hamard, Hôpital des Quinze-vingts, Paris; Yves Lachkar, Fondation Hôpital Saint-Joseph, Paris; MarieHélene Lec, Centre Hospitalier, Lorient; Alain Lefrancois, Hôpital Cochin, Paris; François Malecaze, Hôpital Purpan, Toulouse; Nayla Malek-Chehire, Hôpital Foch, Suresnes; Florence Malet, CHU Morvan, Brest; André Mathis, Hôpital Rangueil, Toulouse; Jean-Philippe Nordmann, Hôpital Tenon, Paris; Guillaume Peigné, 10 Rue Sarrazin, Nantes; Jean-Paul Renard, Hôpital du Val de Grace, Paris; Daniele Rigal, Hôpital St Jacques, Clermont-Ferrand; Jean-Paul Romanet, Hôpital Régional et Universitaire, Grenoble; David Sirbat, 15 Rue du Dome, Strasbourg.

MEMBERS OF THE SWEDISH LATANOPROST STUDY GROUP Coordinating investigator: Mats Söderström, Huddinge University Hospital, Stockholm.

Principal investigators: Torgny Lind, Hudiksvall General Hospital, Hudiksvall; Bertil Lindblom, Sahlgrenska Hospital, Gothenburg; Christina Sörelius and Gunnie Bäckström, Örnsköldsvik General Hospital, Örnsköldsvik; Göran Törnqvist, Skövde General Hospital, Skövde; Lucien Vancea and Birgitta Göthlin, Sundsvall General Hospital, Sundsvall. The results have been presented in part at the American Acad-
emy of Ophthalmology, Annual Meeting, New Orleans, USA, November 1998 .
The study was supported by Pharmacia and Upjohn AB, Clinical Research, Uppsala, Sweden.

1 Alm A, Widengård I, Kjellgren D, et al. Latanoprost administered once daily caused a maintained reduction of intraocular pressure in glaucoma patients treated concomitantly with timolol. Br f Ophthalmol 1995;79:12-16.

2 Alm A, Stjernschantz J, the Scandinavian Latanoprost Study Group. Effects on intraocular pressure and side effects of $0.005 \%$ latanoprost once daily, evening and morning. A comparison with timolol. Ophthalmology 1995; 102:1743-52

3 Camras CB, the United States Latanoprost Study Group. Comparison of latanoprost and timolol in patients with ocular hypertension and glaucoma. A six-month, masked, multicenter trial in the United States. Ophthalmology 1996; 103:138-47.

4 Watson P, Stjernschantz J, the Latanoprost Study Group. A six month randomized double-masked study comparing latanoprost to timolol in open angle glaucoma and ocular hypertension. Ophthalmology 1996;103:126-37.

5 Mishima HK, Masuda K, Kitazawa Y, et al. A comparison of latanoprost and timolol in primary open-angle glaucoma and ocular hypertension. A 12-week study. Arch Ophthalmol 1996;114:929-39.

6 Camras CB, Alm A, Watson P, et al. Latanoprost, a prostaglandin analog, for glaucoma treatment. Efficacy and safety after one year of treatment in 198 patients. Ophthalmology 1996;103:1916-24.

7 Watson PG, the Latanoprost Study Group. Latanoprosttwo years' experience of its use in the United Kingdom. Ophthalmology 1998;105:82-7.

8 Stjernschantz J, Selén G, Sjöquist B, et al. Preclinical pharmacology of latanoprost, a phenyl substituted PGF analogue. Adv Prostaglandin Thromboxane Leukot Res 1995; 23:513-8.

9 Toris CB, Camras CB, Yablonski ME. Effects of PhXA41, a new prostaglandin $\mathrm{F}_{2 \alpha}$ analogue, on aqueous humor dynamics in human eyes. Ophthalmology 1993;100:1297304 .

10 Ziai N, Dolan JW, Kacere RD, et al. The effects on aqueous dynamics of PhXA41, a new prostaglandin $\mathrm{F}_{2 \alpha}$ analogue, after topical application in normal and ocular hypertensive human eyes. Arch Ophthalmol 1993;111:1351-8.

11 illumsen J, Alm A. The effect on intraocular pressure of adding prostaglandin $\mathrm{F}_{2 \mathrm{a}}$-isopropylester to timolol in patients with open angle glaucoma. A randomized, masked placebo-controlled study. Arch Ophthalmol 1990;108:11025.

12 Lee PY, Shao H, Camras CB, et al. Additivity of prostaglandin isopropyl ester to timolol in glaucoma patients. Ophthalmology 1991;98:1079-82.

13 Uusitalo RJ, Palkama A. Long-term evaluation of timolol. Acta Ophthalmol 1989;67:573-81.

14 Weinreb RN. Compliance with medical treatments of glaucoma. F Glaucoma 1992;1:134-6.

15 Boger WP III, Puliafito CA, Steinert RF, et al. Long-term experience with timolol ophthalmic solution in patients with open-angle glaucoma. Ophthalmology 1978;85:25967.

16 Schlecht LP, Brubaker RF. The effects of withdrawal of timolol in chronically treated glaucoma patients. Ophthalmology 1988;95:1212-6.

17 Söderström MB, Wallin Ö, Granström P-A, et al. Timololpilocarpine combined vs timolol and pilocarpine given separately. Am f Ophthalmol 1989;107:465-70. 